
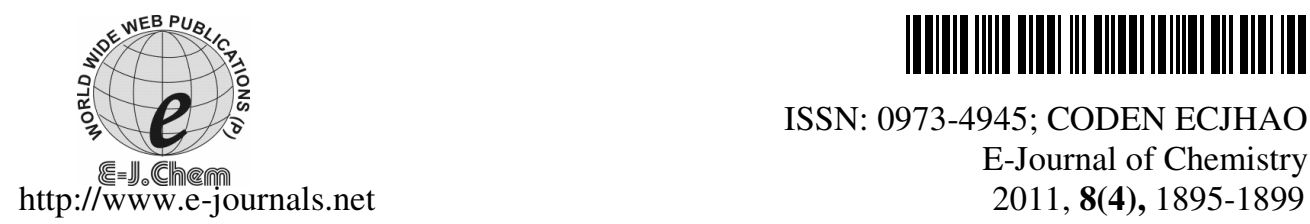

ISSN: 0973-4945; CODEN ECJHAO

E-Journal of Chemistry

2011, 8(4), 1895-1899

\title{
Efficient, One-Pot Synthesis of Tetrahydrobenzo $[a]$ xanthen-11-ones and Dibenzo[a,j]xanthenes Using Trichloroacetic Acid as a Solid Heterogeneous Catalyst Under Solvent-Free Conditions
}

\author{
ZAHED KARIMI-JABERI", S. ZOLEYKHA ABBASI, \\ BAHARAK POOLADIAN and MARZIYEH JOKAR
}

Department of Chemistry, Firoozabad Branch, Islamic Azad University, P.O. Box 74715-117 Firoozabad, Fars, Iran

zahed.karimi@yahoo.com

Received 2 January 2011; Accepted 28 February 2011

\begin{abstract}
A simple and efficient method have been described for the synthesis of 12-aryl-8,9,10,12-tetrahydrobenzo[a]xanthen-11-one derivatives employing a one-pot, three-component reaction of aryl aldehydes, 2-naphthol and dimedone in the presence of trichloroacetic acid under solvent-free conditions. Also the condensation of 2-naphthol with alkyl or aryl aldehydes in the presence of trichloroacetic acid under solvent-free media to afford the corresponding 14-aryl or alkyl -14H-dibenzo [a.j]xanthenes in excellent yields and short reaction times is described.
\end{abstract}

Keywords: Dibenzo $[a . j]$ xanthenes, Dimedone, 2-Naphthol, Tetrahydrobenzo[ $a]$ xanthen-11-ones, Trichloroacetic acid

\section{Introduction}

Xanthenes and its derivatives are known as an important class of heterocyclic compounds widely used as leco-dye ${ }^{1}$, in laser technology ${ }^{2}$ and $\mathrm{pH}$ sensitive fluorescent materials ${ }^{3}$. Although not widely found in nature, xanthenes and compounds based on these core templates exhibit a broad spectrum of pharmaceutical activities ${ }^{4}$. These compounds are also utilized as antagonists for paralyzing action of zoxazolamine ${ }^{5}$ and in photodynamic therapy ${ }^{6}$. Thus a broad utility range has made xanthenes prime synthetic candidates thereby accentuating the need to develop newer synthetic routes for scaffold manipulation of xanthene derivatives. A few methods have been developed for the synthesis of 12-aryl-8,9, 
10,12-tetrahydrobenzo[ $a]$ xanthen-11-one derivatives. One-pot three-component condensation of aldehydes, 2-naphthol and cyclic 1,3-dicarbonyl compound is the most convenient method for the preparation of these compounds. In this context some methods and catalysts have been reported $^{7-12}$. Furthermore, the synthesis of $14 H$-dibenzo[a,j]xanthenes and its analogous can be prepared by reaction of 2-naphthol with aldehydes in the presence of a catalyst ${ }^{13-17}$. However, these methodologies show varying degrees of success as well as limitations due to use of toxic organic solvents, expensive catalyst, prolonged reaction times, the requirement of special apparatus, or harsh reaction conditions. Thus, there is a certain need for the development of an alternative route for the production of these derivatives, which surpasses those limitations.

Following our systematic studies directed towards the development of practical, safe, and environmentally friendly procedures for several important organic transformations ${ }^{17-19}$, we describe an efficient method for the synthesis of tetrahydrobenzo[ $a]$ xanthen-11-ones through three-component reactions of aldehydes, 2-naphthol and dimedone using trichloroacetic acid $\left(\mathrm{CCl}_{3} \mathrm{COOH}\right)$ as a catalyst under solvent-free conditions (Scheme 1-2).

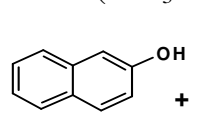

1<smiles>[R]C=O</smiles><smiles>CC1(C(=O)O)CC(=O)CC(=O)C1</smiles><smiles></smiles>

4a-1

\section{Experimental}

\section{Scheme 1}

General procedure for the synthesis of tetrahydrobenzo[a]xanthen-11-ones

A mixture of 2-naphthol $(1 \mathrm{mmol})$, aldehyde $(1 \mathrm{mmol})$, dimedone $(1.2 \mathrm{mmol})$ and trichloroacetic acid $(0.1 \mathrm{~g})$ was stirred at $120{ }^{\circ} \mathrm{C}$ for the appropriate time indicated in Table 1. The progress of reactions was monitored by TLC (ethyl acetate/n-hexane=1/4). After completion of the reaction, a solid was obtained. It was washed with water and purified by recrystalization from ethanol to afford pure products.

General procedure for the synthesis of 14-alkyl- or aryl-14H-dibenzo[a,j]xanthenes

A mixture of aldehyde (1 mmol), 2-naphthol $(2 \mathrm{mmol})$ and trichloroacetic acid $(0.1 \mathrm{~g})$ was stirred at $120{ }^{\circ} \mathrm{C}$ for the appropriate time indicated in Table 1 . The progress of reactions was monitored by TLC (ethyl acetate/n-hexane $=1 / 4$ ). After completion of the reaction, the reaction mixture was cooled to $25{ }^{\circ} \mathrm{C}$ and water $(10 \mathrm{~mL})$ was added and the mixture was stirred for $10 \mathrm{~min}$. The obtained solid was collected by filtration and purified by recrystallization from ethanol.

Table 1. Synthesis of tetrahydrobenzo[a]xanthen-11-ones

\begin{tabular}{cccccc}
\hline Entry & $\mathrm{R}$ & product & Time, min & Yield, \% & m.p., ${ }^{\circ} \mathrm{C}^{[\text {ref.] }}$ \\
\hline 1 & $4-\mathrm{ClC}_{6} \mathrm{H}_{4}$ & $\mathbf{4 a}$ & 10 & 94 & $176-179^{[11]}$ \\
2 & $\mathrm{C}_{6} \mathrm{H}_{5}$ & $\mathbf{4 b}$ & 30 & 73 & $151-154^{[11]}$ \\
3 & $4-\mathrm{CH}_{3} \mathrm{OC}_{6} \mathrm{H}_{4}$ & $\mathbf{4 c}$ & 20 & 75 & $198-202^{[11]}$ \\
4 & $4-\mathrm{NO}_{2} \mathrm{C}_{6} \mathrm{H}_{4}$ & $\mathbf{4 d}$ & 15 & 98 & $176-179^{[11]}$ \\
5 & $3-\mathrm{NO}_{2} \mathrm{C}_{6} \mathrm{H}_{4}$ & $\mathbf{4 e}$ & 10 & 94 & $165-168^{[11]}$ \\
6 & $2,4-\mathrm{Cl}_{2} \mathrm{C}_{6} \mathrm{H}_{3}$ & $\mathbf{4 f}$ & 10 & 90 & $179-181^{[11]}$ \\
7 & $4-\mathrm{CH}_{3} \mathrm{C}_{6} \mathrm{H}_{4}$ & $\mathbf{4 g}$ & 25 & 86 & $173-175^{[11]}$ \\
8 & $3-\mathrm{CH}_{3} \mathrm{OC}_{6} \mathrm{H}_{4}$ & $\mathbf{4 h}$ & 15 & 66 & $199-200^{[12]}$ \\
9 & $2-\mathrm{NO}_{2} \mathrm{C}_{6} \mathrm{H}_{4}$ & $\mathbf{4 i}$ & 15 & 72 & $219-221^{[12]}$ \\
10 & $2-\mathrm{CH}_{3} \mathrm{OC}_{6} \mathrm{H}_{4}$ & $\mathbf{4 j}$ & 15 & 67 & $163-166^{[11]}$ \\
11 & $2-\mathrm{ClC}_{6} \mathrm{H}_{4}$ & $\mathbf{4 k}$ & 15 & 84 & $173-177^{[11]}$ \\
12 & $4-\mathrm{FC}_{6} \mathrm{H}_{4}$ & $\mathbf{4 l}$ & 20 & 73 & $188-190^{[9]}$ \\
\hline
\end{tabular}




\section{Spectral data for selected products}

9,9-Dimethyl-12-(2-methoxyphenyl)-8,9,10,12-tetrahydrobenzo[a]xanthen-11-one (4j) mp 163-166 ${ }^{\circ} \mathrm{C}$. IR (KBr): 3072, 2930, 1649, 1376, 1231, 1170, $1029 \mathrm{~cm}^{-1} .1 \mathrm{H} \mathrm{NMR}\left(\mathrm{CDCl}_{3}\right)$ : $\delta 8.33(\mathrm{~d}, \mathrm{~J}=8.4 \mathrm{~Hz}, 1 \mathrm{H}), 7.78-7.72(\mathrm{~m}, 2 \mathrm{H}), 7.49-7.29(\mathrm{~m}, 4 \mathrm{H}), 7.10-7.05(\mathrm{~m}, 1 \mathrm{H}), 6.85-6.80$ (m, 2H), 6.00 (s, 1H), 3.99 (s, 3H), 2.65 (d, J=17.6 Hz, 1H), 2.60 (d, J=17.6 Hz, 1H), 2.33 (d, $\mathrm{J}=16.4 \mathrm{~Hz}, 1 \mathrm{H}), 2.24(\mathrm{~d}, \mathrm{~J}=16.4 \mathrm{~Hz}, 1 \mathrm{H}), 1.16(\mathrm{~s}, 3 \mathrm{H}), 1.03(\mathrm{~s}, 3 \mathrm{H}) .{ }^{13} \mathrm{C} \mathrm{NMR}\left(\mathrm{CDCl}_{3}\right): \delta$ $196.8,164.2,156.3,147.6,133.2,131.8,131.2,130.5,128.3,128.1,127.5,126.7,124.6$, 123.9, 120.6, 118.2, 116.9, 113.6, 111.4, 55.8, 50.8, 41.4, 32.9, 32.2, 29.4, 27.0.

9, 9-Dimethyl-12-(4-florophenyl)-8,9,10,12-tetrahydrobenzo[a]xanthen-11-one (4l) mp 188-190 ${ }^{\circ} \mathrm{C}$. IR (KBr): 3072, 3039, 3003, 2954, 1649, 1595, 1506, 1464, 1372, 1320, 1293, 1226, 1185, 1163, 1143, 1120, 1093, 1069, 1016, 974, 936, 839, 813, 767, 743, 715, $654 \mathrm{~cm}^{-1} .{ }^{1} \mathrm{H}-\mathrm{NMR}\left(\mathrm{CDCl}_{3}\right): \delta 7.96(\mathrm{~d}, \mathrm{~J}=8.4 \mathrm{~Hz}, 1 \mathrm{H}), 7.83-7.95(\mathrm{~m}, 2 \mathrm{H}), 7.49-7.31$ $(\mathrm{m}, 4 \mathrm{H}), 6.92-6.87(\mathrm{~m}, 2 \mathrm{H}), 5.73(\mathrm{~s}, 1 \mathrm{H}), 2.60(\mathrm{~s}, 2 \mathrm{H}), 2.35(\mathrm{~d}, \mathrm{~J}=16.4 \mathrm{~Hz}, 1 \mathrm{H}), 2.28$ $(\mathrm{d}, \mathrm{J}=16.4 \mathrm{~Hz}, 1 \mathrm{H}), 1.15$ (s, 3H), 0.99 (s, 3H). ${ }^{13} \mathrm{C} \mathrm{NMR}\left(\mathrm{CDCl}_{3}\right): \delta 197.3,164.3,162.6$, $160.7,148.2$, 141.0, 140.9, 131.9, 131.7, 130.4, 130.3, 129.4, 128.9, 127.5, 125.4, 123.9, $117.8,117.5,115.5,115.4,114.5,51.3,41.8,34.4,32.7,29.7,27.5$.

\section{4-(2,4-Dichlorophenyl)-14H-dibenzo[a,j]xanthene (5e)}

mp 250-252 ${ }^{\circ} \mathrm{C}$. IR (KBr): 3057, 2920, 1592, 1516, 1463, 1403, 1247, 1208, 1141, 1101, $1073,962,829,836,807,741,699,608 \mathrm{~cm}^{-1} .{ }^{1} \mathrm{H}-\mathrm{NMR}\left(\mathrm{CDCl}_{3}\right): \delta 6.74(\mathrm{~s}, 1 \mathrm{H}), 6.89$ $(\mathrm{d}, \mathrm{J}=8.7 \mathrm{~Hz}, 1 \mathrm{H}), 7.27-7.32(\mathrm{~m}, 2 \mathrm{H}), 7.42-7.50(\mathrm{~m}, 4 \mathrm{H}), 7.56-7.66(\mathrm{~m}, 2 \mathrm{H}), 7.79-7.85$ $(\mathrm{m}, 4 \mathrm{H}), 8.65(\mathrm{~d}, \mathrm{~J}=8.2 \mathrm{~Hz}, 2 \mathrm{H})$.

\section{4- (3-Methoxyphenyl)-14H-dibenzo[a,j]-xanthene (5i)}

mp 180-182 ${ }^{\circ} \mathrm{C}$. IR(KBr): 3057, 290, 1593, 1515, 1486, 1457, 1433, 1400, 1048, 692, 815, 775, 743, $698 \mathrm{~cm}^{-1} .{ }^{1} \mathrm{H}-\mathrm{NMR}\left(\mathrm{CDCl}_{3}\right): \delta 3.63(\mathrm{~s}, 3 \mathrm{H}), 6.46(\mathrm{~s}, 1 \mathrm{H}), 6.53(\mathrm{~d}, \mathrm{~J}=7.2 \mathrm{~Hz}, 1 \mathrm{H})$, 7.07-7.26 (m, 3H), 7.39-7.63 (m, 6H), 7.77-7.78 (m, 4H), 8.41(d, J=8.2Hz, 2H).

\section{4-(4-Bromophenyl)-14H-dibenzo[a,j]-xanthene (5k)}

mp 303-305 ${ }^{\circ} \mathrm{C}$. IR(KBr): 3056, 2922, 1621, 1591, 1513, 1481, 1392, 1240, 1231, 1207 , $1143,1073,962,807,772,741 \mathrm{~cm}^{-1} .{ }^{1} \mathrm{H}-\mathrm{NMR}\left(250 \mathrm{MHz}, \mathrm{CDCl}_{3}\right): \delta 6.45(\mathrm{~s}, 1 \mathrm{H}), 7.79-7.85$ (m, 4H), 7.24-7.61 (m, 10H), 8.31(d, J=8.2Hz, 2H).

\section{Results and Discussion}

To optimize the reaction conditions for the synthesis of tetrahydrobenzo[ $a]$ xanthen-11-one, treatment of 4-chlorobenzaldehyde and 2-naphthol with dimedone was used as a model reaction. Reactions at different conditions and various molar ratios of substrates in the presence of $\mathrm{CCl}_{3} \mathrm{COOH}$ revealed that this acid gives the corresponding tetrahydrobenzo[a]xanthen-11-one with $94 \%$ yield in $10 \mathrm{~min}$ under solvent-free condition at $120{ }^{\circ} \mathrm{C}$. To illustrate the need of trichloroacetic acid for these reactions an experiment was conducted in the absence of trichloroacetic acid. The yield in this case was about $10 \%$ after $12 \mathrm{~h}$. Obviously, the trichloroacetic acid is an important component of the reaction. The reaction was then attempted under similar conditions in the presence of different acids. The reactions carried out in the presence of $\mathrm{CH}_{3} \mathrm{COOH}$ were sluggish and incomplete even after $5 \mathrm{~h}$. Further, trichloroacetic acid is a stable solid, non-volatile, inexpensive, commercially available and easy-to-handle reagent. 
The scope and generality of this method is illustrated with respect to various aromatic aldehydes. An array of structurally and electronically divergent aromatic aldehydes, dimedone and 2-naphthol were tested and the results are summarized in Table 1. The present methodology afforded high yields of the products within short times (10-30 min). In general, aldehydes bearing electron-donating groups need slightly longer times to complete the reaction as compared to aldehydes containing electron-withdrawing groups. Various functionalities present in the aryl aldehydes, such as chloro, flouro, nitro, methoxy and methyl groups were tolerated under these conditions at $120^{\circ} \mathrm{C}$ (Table 1).

Under the same conditions, it was observed that trichloroacetic acid catalyzed reaction of 2-naphthol and aldehyde under solvent free conditions at $120{ }^{\circ} \mathrm{C}$ resulted to the formation of the corresponding dibenzo[a,j]xanthenes (Scheme 2). The results are compiled in Table 2.

The application of this protocol was extended to a variety of aromatic aldehydes. The reactions proceeded smoothly with different aldehydes substituted with electrondonating/electron-withdrawing groups giving excellent yields (Table 2, entries 1-12). Interestingly, aliphatic aldehydes also gave the expected dibenzo[a,j]xanthene derivatives in good yields (Table 2, entries 13-15).

Table 2. Synthesis of 14-alkyl- or aryl-14H-dibenzo[a,j]xanthenes

\begin{tabular}{|c|c|c|c|c|c|}
\hline Entry & $\mathrm{R}$ & product & Time, min & Yield, \% & m.p., ${ }^{\circ} \mathrm{C}$ \\
\hline 1 & $\mathrm{C}_{6} \mathrm{H}_{5}$ & $5 a$ & 15 & 88 & $190-193$ \\
\hline 2 & $2-\mathrm{ClC}_{6} \mathrm{H}_{4}$ & $5 \mathbf{b}$ & 5 & 83 & $216-218$ \\
\hline 3 & $4-\mathrm{CH}_{3} \mathrm{OC}_{6} \mathrm{H}_{4}$ & $5 c$ & 15 & 80 & $209-210$ \\
\hline 4 & $4-\mathrm{ClC}_{6} \mathrm{H}_{4}$ & $5 d$ & 10 & 85 & $295-298$ \\
\hline 5 & 2,4- $\mathrm{Cl}_{2} \mathrm{C}_{6} \mathrm{H}_{3}$ & $5 e$ & 5 & 86 & $250-252$ \\
\hline 6 & $3-\mathrm{NO}_{2} \mathrm{C}_{6} \mathrm{H}_{4}$ & $5 f$ & 10 & 93 & $211-215$ \\
\hline 7 & $4-\mathrm{NO}_{2} \mathrm{C}_{6} \mathrm{H}_{4}$ & $5 g$ & 10 & 93 & $325-326$ \\
\hline 8 & $4-\mathrm{CH}_{3} \mathrm{C}_{6} \mathrm{H}_{4}$ & $5 \mathrm{~h}$ & 15 & 72 & $227-232$ \\
\hline 9 & $3-\mathrm{CH}_{3} \mathrm{OC}_{6} \mathrm{H}_{4}$ & $5 \mathbf{i}$ & 15 & 80 & $180-182$ \\
\hline 10 & $2-\mathrm{CH}_{3} \mathrm{OC}_{6} \mathrm{H}_{4}$ & $5 \mathbf{j}$ & 15 & 66 & 264-268 \\
\hline 11 & $4-\mathrm{BrC}_{6} \mathrm{H}_{4}$ & $5 \mathbf{k}$ & 8 & 80 & 303-305 \\
\hline 12 & 4- $\mathrm{CNC}_{6} \mathrm{H}_{4}$ & 51 & 5 & 90 & $329-332$ \\
\hline 13 & $\mathrm{CH}_{3} \mathrm{CH}_{2}$ & $5 \mathrm{~m}$ & 18 & 40 & $153-156$ \\
\hline 14 & $\mathrm{CH}_{3} \mathrm{CH}_{2} \mathrm{CH}_{2}$ & $5 n$ & 18 & 50 & $156-158$ \\
\hline 15 & $\mathrm{CH}_{3} \mathrm{CH}_{2} \mathrm{CH}_{2} \mathrm{CH}_{2}$ & 50 & 18 & 50 & $96-98$ \\
\hline
\end{tabular}

\section{Scheme 2}

As reported in the literatures ${ }^{11-12}$, the reaction of 2-naphthol with aromatic aldehydes in the presence of acid catalyst is known to give ortho-quinone methides (O-QMs). The same $\mathrm{O}-\mathrm{QMs}$, generated in-situ, have been reacted with dimedone or 2-naphthol, followed by cyclization to form tetrahydrobenzo[a]xanthen-11-one or dibenzo[a,j]xanthene derivatives, accompanied by loss of $\mathrm{H}_{2} \mathrm{O}$. The proposed mechanism for the trichloroacetic acid catalyzed preparation of 12-aryl-8,9,10,12-tetrahydrobenzo[ $a$ ]xanthen-11-ones or 14-substituted-14Hdibenzo[a,j]xanthenes is shown in Scheme 3. 


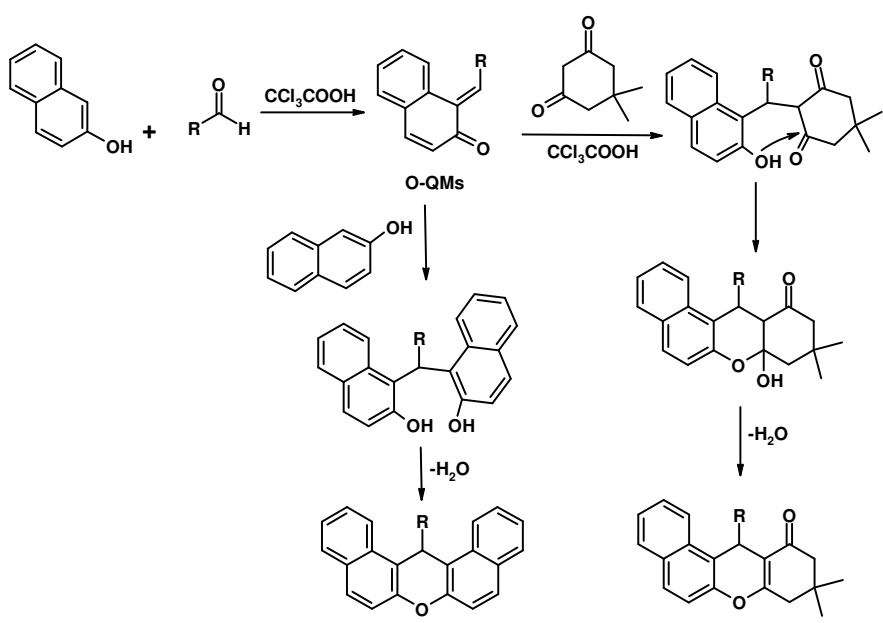

Scheme 3

All products were identified by ${ }^{1} \mathrm{H}-\mathrm{NMR},{ }^{13} \mathrm{C}$ NMR, IR and mass spectroscopic methods and the results were confirmed by comparison with those available in the literature.

\section{Conclusion}

In conclusion this paper describes a convenient and efficient process for the synthesis of tetrahydrobenzo[a]xanthen-11-ones and dibenzo[a,j]xanthenes in the presence of trichloroacetic acid under solvent-free conditions at $120{ }^{\circ} \mathrm{C}$. This method offers some advantages in terms of simplicity of performance, low reaction times, solvent-free condition, low cost and it follows along the line of green chemistry. The catalyst is readily available and inexpensive and can conveniently be handled and removed from the reaction mixture. In many cases, the products crystallized directly from the reaction mixture in high purity.

\section{References}

1. Griffiths J and Lee W J, Dyes Pigments, 2003, 57, 107.

2. Ahmad M, King T A, Ko D K, Cha B H and Lee J, J Phys D Appl Phys., 2002, 35, 1473.

3. Knight C G and Stephens T, Biochem J., 1989, 258, 683-687.

4. Poupelin J P, Saint-Ruf G, Foussard-Blanpin O, Marcisse G, Uchida-Ernouf G and Lacroix R, Eur J Med Chem., 1978, 13, 67.

5. Saint-Ruf G, Hieu H T and Poupelin J P, Naturwissenschaften, 1975, 62, 584-585.

6. Ion R M, Frackowiak D, Planner A and Wiktorowicz K, Acta Biochim Pol..,1998, 45, 833.

7. Li J, Tang W, Lu L and Su W, Tetrahedron Lett., 2008, 49, 7117-7120.

8. Das B, Laxminarayana K, Krishnaiah M and Srinivas Y, Synlett., 2007, 3107-3112.

9. Khurana J M and Magoo D, Tetrahedron Lett., 2009, 50, 4777.

10. Kumar A, Sharma S, Maurya R A and Sarkar J, J Comb Chem., 2010, 12, 20.

11. Nandi G C, Samai S, Kumar R and Singh M S, Tetrahedron, 2009, 65, 7129.

12. Li J, Lu L and Su W, Tetrahedron Lett., 2010, 51, 2434-2437.

13. Karimi-Jaberi Z and Hashemi M M, Monatsh Chem., 2008, 139, 605.

14. Pasha M A and Jayashankara V P, Bioorg Med Chem Lett., 2007, 17, 621.

15. Bigdeli M A, Heravi, M M and Mahdavinia G H, Catal Commun., 2007, 8, 1595.

16. Kumar R, Nandi G C, Verma R K and Singh M S, Tetrahedron Lett., 2010, 51, 442-445.

17. Karimi-Jaberi Z and Keshavarzi M, Chin Chem Lett., 2010, 21, 547.

18. Karimi-Jaberi Z and Amiri M, Heteroatom Chem., 2010, 21, 96.

19. Karimi-Jaberi Z, Amiri M and Sadeghi N, Synth Commun., 2010, 40, 2948-2963. 


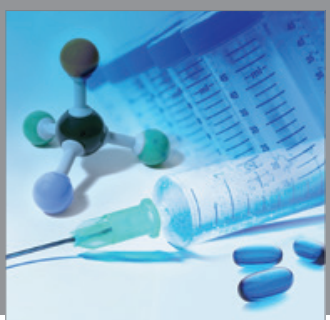

International Journal of

Medicinal Chemistry

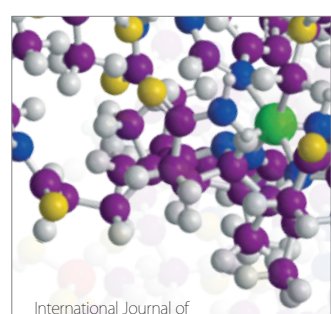

Carbohydrate Chemistry

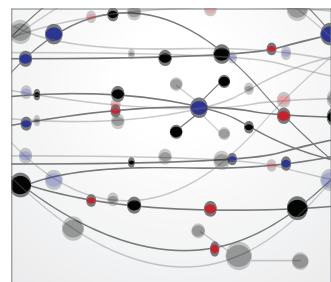

The Scientific World Journal
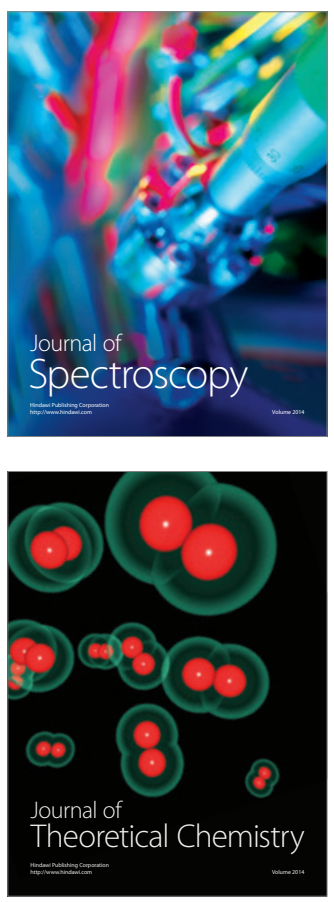
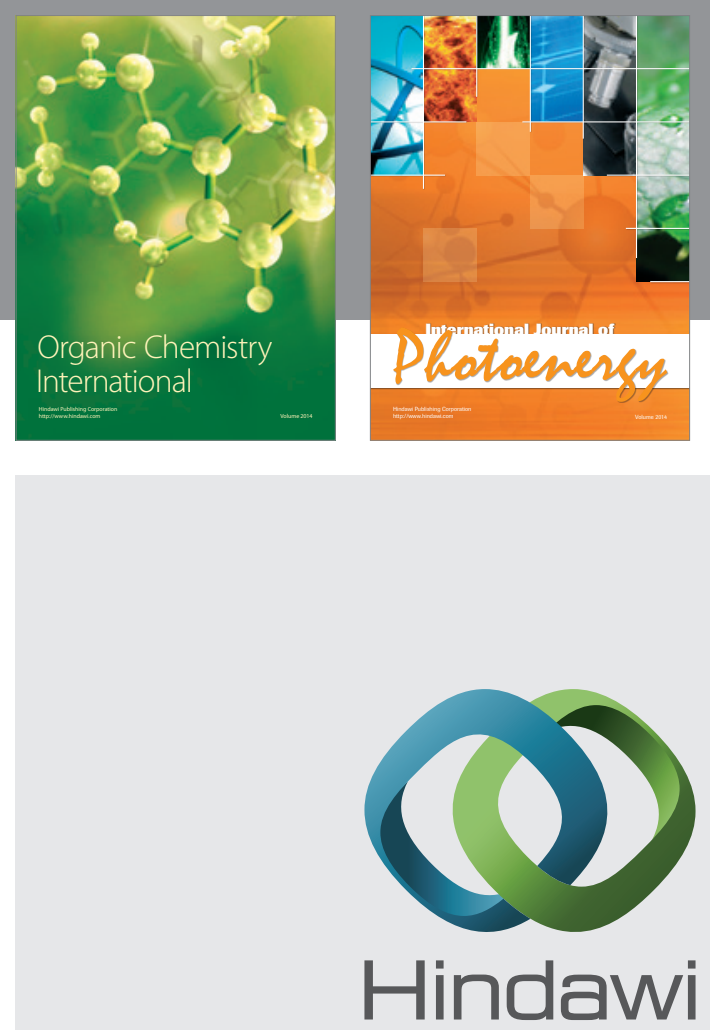

Submit your manuscripts at

http://www.hindawi.com
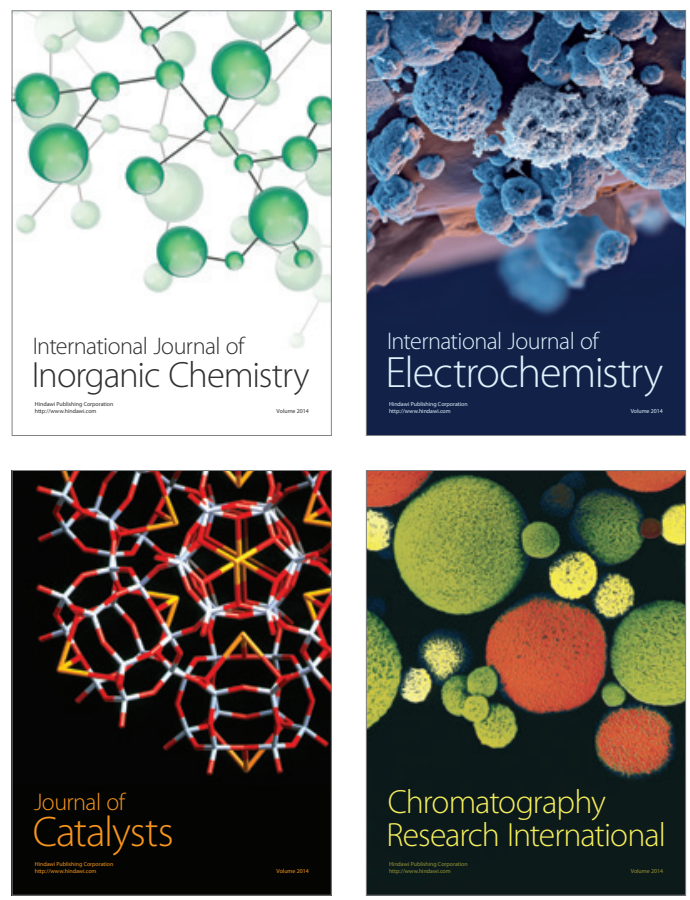
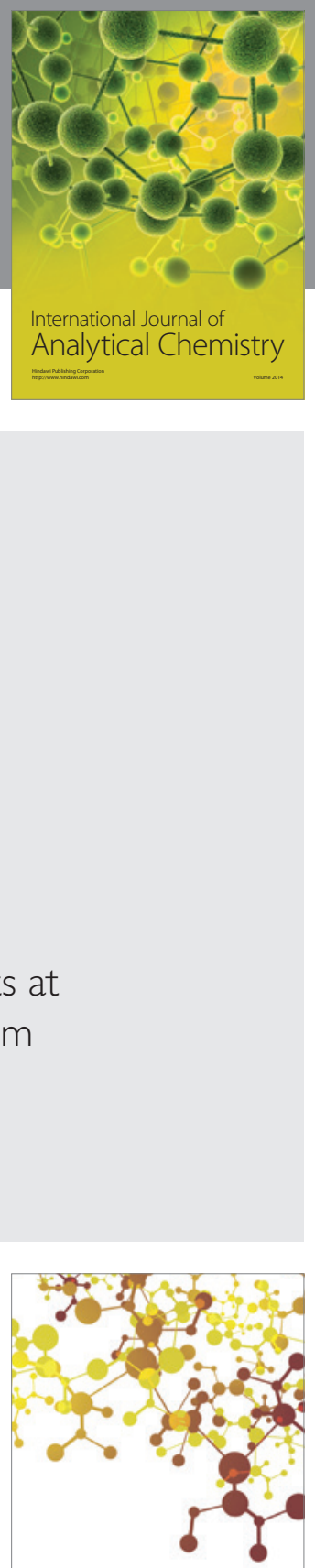

Journal of

Applied Chemistry
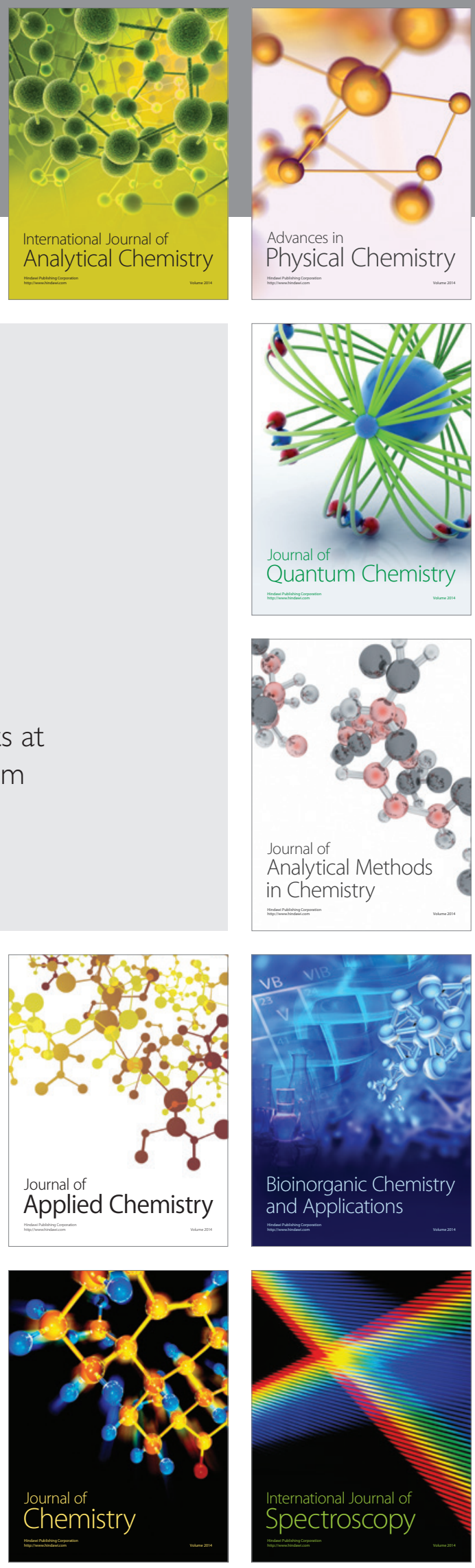